\title{
UTERINE RUPTURE AT 31 WEEKS AND ITS OUTCOME- A CASE REPORT
}

\author{
Valsamma Abraham ${ }^{1}$, Shyni Varghese2, Plavelel Varkey Varghese ${ }^{3}$, Inderpreet Sohi', Sajan Sebastin ${ }^{5}$
}

1 Professor, Department of Anaesthesia, Christian Medical College, Ludhiana.

${ }^{2}$ Associate Professor, Department of Gynaecology, Christian Medical College, Ludhiana.

${ }^{3}$ Professor, Department of Neonatology, Christian Medical College, Ludhiana.

${ }^{4}$ Professor, Department of Neonatology, Christian Medical College, Ludhiana.

${ }^{5}$ Assistant Professor, Department of Anaesthesia, Christian Medical College, Ludhiana.

ABSTRACT

\section{BACKGROUND}

Uterine rupture is a serious life-threatening event that may lead to peripartum hysterectomy, haemorrhagic shock and even maternal and foetal mortality. Mortality rate increases with late presentation. Further, the foetal survival is jeopardised if it is a pre-term. We present a case of uterine rupture with foetal resuscitation, which is extremely rare at 31 weeks of gestation.

\section{KEYWORDS}

Rupture Uterus, Pre-Term, C-Section, Perinatal Outcome.

HOW TO CITE THIS ARTICLE: Abraham V, Varghese S, Varghese PV, et al. Uterine rupture at 31 weeks and its outcome- a case report. J. Evolution Med. Dent. Sci. 2017;6(34):2863-2864, DOI: 10.14260/Jemds/2017/617

\section{BACKGROUND}

Uterine rupture is a serious life-threatening event that may lead to peripartum hysterectomy, haemorrhagic shock and even maternal and foetal mortality.(1) Uterine rupture is a recognised complication of vaginal birth after caesarean section with serious maternal and foetal outcomes. Prostaglandins and Oxytocics to induce and augment labour increase the risk of uterine rupture 2 - 3 folds.(2) We present this case of uterine rupture at 31 weeks of gestation with neonatal survival after taking informed written consent from the patient.

\section{CASE DESCRIPTION}

28 years old lady married for 10 years. $G_{3} P_{2+0}, L_{0}$ at 31 weeks of gestation were referred from ESI hospital as a case of rupture uterus. Initially, she was taken to a Centre, where an untrained person did a P/V examination and gave 20 units of Oxytocin IM to augment labour.

O/E: She was in severe pain, conscious, oriented, tachypnoeic with severe pallor, HR 130/min, BP 80/? In the emergency room she was given 1 litre crystalloid $+500 \mathrm{~mL}$ colloid. Urine was clear, abdomen was tense with guarding and tenderness, uterine contour could not be made out well. Foetal heart sound was not localised.

$\mathrm{P} / \mathrm{V}$ finding- Cervix was pushed posteriorly, OS closed and foetal head felt superficially through anterior fornix. A diagnosis of rupture uterus with intrauterine foetal death was made and she was immediately resuscitated with 1 litre fluid and taken to operation theatre for laparotomy. In the theatre, she was given 1 litre of normal saline and $500 \mathrm{~mL}$ of colloid 1 unit of blood was also started. She was operated under general anaesthesia.

Intraoperative findings: $500 \mathrm{~mL}$ of blood with $150 \mathrm{gm}$ of clots was present in the peritoneal cavity. Lower segment

Financial or Other, Competing Interest: None.

Submission 07-11-2016, Peer Review 15-04-2017,

Acceptance 21-04-2017, Published 27-04-2017.

Corresponding Author:

Dr. Valsamma Abraham,

Professor, Department of Anaesthesia,

Christian Medical College, Ludhiana.

E-mail: dr_valsa@yahoo.com

DOI: $10.14260 /$ jemds $/ 2017 / 617$ was intact. Previous classical scar rupture was seen all along the scar with $8 \mathrm{~cm}$ in length and extending up to fundus upwards. Bladder was found intact. Membrane was intact with the clots attached. A female baby was taken out by a separate lower segment incision. Baby was limp and cyanosed, gasped once. The anaesthesia team immediately resuscitated the baby with endotracheal intubation and positive pressure ventilation. The neonatologist was called and the baby was handed over to them. Baby required ventilator support for 1 day and intensive care for another 3 weeks after which she was discharged in a satisfactory condition with a weight of 1560 gms.

\section{DISCUSSION}

The full thickness defect of the myometrium and uterine serosa or myometrial disruption extending to the bladder or broad ligament is termed uterine rupture.(3) While a partial thickness defect with intact uterine serosa, which may progress to rupture is termed as uterine dehiscence.(3) Uterine rupture occurring in an unscarred uterus is very rare with an incidence of $0.5-2.0 / 10000$, largely confined to labouring multiparas.(4) However, isolated occurrences of pre-labour and primiparous uterine rupture are described.(5) Previous caesarean section incision or other uterine scars, uterine anomalies, grand multiparity, tumours, use of oxytocin, placenta percreta and foetal anomalies are postulated risk factors for uterine rupture.(6)

Uterine scar is site for the vast majority of uterine dehiscence and rupture. The atrophic, inelastic nature of the scar renders it less adaptive to force in labour, predisposing to scar rupture. However, a particularly rigid anterior lower segment may cause abnormal distribution of force. Due to rigid anterior uterine scar, the posterior wall may be excessively shortened and thinned out during retraction. This catalyses atypical uterine rupture via healthy tissue. Any factor compromising uterine structural integrity or causing abnormal distribution of force can precipitate uterine rupture. The site of uterine rupture is unpredictable and may be atypical. Few cases of posterior uterine rupture are reported in the literature. A complete UR involves the entire uterine wall leading to a direct connection between the peritoneal space and the uterine cavity, whereas a cover of 
visceral, peritoneum of the broad ligament is left over the uterus in case of an incomplete UR.(2)

In women with two or more prior caesareans, the rate of rupture rises as high as 3.9 percent. (7) The underlying factors for UR include a poor referral system, non-attendance to antenatal care, delay in seeking medical care and delay of essential intervention.(6)

Low socio-economic status, the delivery of babies $>3.5$ $\mathrm{kg}$, HIV positivity and history of previous caesarean section are other postulated risk factors for UR. Oxytocin stimulation and previous scars are assumed to be the direct causes of UR in developed countries, while obstructed labour is the main culprit in developing countries. Maternofoetal outcome of UR vary from country to country depending on the availability and quality of health facilities.(6)

Modes of presentation in UR may differ in scarred and unscarred uterus. Hypotension and intrauterine death occur frequently in the unscarred UR, whereas abdominal tenderness and foetal distress are more common in the scarred uteri. Rupture of the unscarred uterus varies more hazardless foetomaternal risk compared to scarred uterus. (2) Even though the mode of presentation was similar for patients with or without CS history, instability, deterioration of vital parameters and vaginal bleeding after labour must remind likelihood of UR.

Hysterectomy, whether total or subtotal, was the main surgical procedure in case of UR. In circumstances where preservation of fertility is an issue to be remembered, suture repair can be considered. However, UR has a potential for mortality and cost-benefit ratio must be evaluated very well. Improved access to resources and service may aid in the avoidance of the vast majority of these mortalities and morbidities. Hypovolaemic shock is claimed to be the main cause of death and rapid transfer of these patients to tertiary care centres is imperative. A high index of suspicion and quick referral to a well-equipped centre may reduce the incidence of this condition. All patients with a history of caesarean section should deliver in hospitals with facilities for surgery and blood transfusion. Regular antenatal care and meticulous screening of high risk patients are very important for effective prevention.(8)

Close monitoring of maternal and foetal response to uterine stimulants is mandatory to avoid complications of obstructed labour and overuse of uterine stimulants. Our patient was a multigravida and she was given Inj. Oxytocin I/M 20 units by an untrained person is the cause of uterine rupture. This patient was only 31 weeks gestation from a poor socio-economic background developed sudden abdominal pain after I/M Inj. of oxytocin. She was examined vaginally by the untrained person and thus augmented the pain. Usually, uterine rupture reported in the full-term pregnancy where the uterus is thinned out. This patient was presented to us with severe abdominal pain and in shock. The uterine rupture was from the classical C-section site and the membrane was present. The foetal delivery was done by a lower segment C-section. Since there was no FHS present, paediatricians were not called. This baby was resuscitated by a senior anaesthetist who was present in the theatre. Few cases are reported in the literature about the neonatal survival after uterine rupture at term pregnancy and preterm. This baby who was of 31 weeks gestation survived the hypovolaemic shock. Baby was ventilated overnight and extubated next morning. She was discharged after 3 weeks of heavy antibiotics in a good condition. Very few cases are reported in the literature about the survival of 31 weeks gestation baby after the uterine rupture. As the patient was only 28 years, repair of uterine rupture and bilateral tubectomy done.

In conclusion UR constitutes a major risk for foetomaternal morbidity and mortality. Early diagnosis and prompt exploratory laparotomy can be necessary to save the mother and the foetus from the complication. Increased accessibility to antenatal care as well as a functional referral system for pregnant women may aid in prevention of UR. The physicians and the delivery institution should be prepared to provide emergency surgical and neonatal care in the event of uterine rupture.

\section{REFERENCES}

[1] Chuni N. Analysis of uterine rupture in a tertiary center in Eastern Nepal: lessons for obstetric care. J Obstet Gynaecol Res 2006;32(6):574-9.

[2] Navaratnam K, Ulaganathan P, Akhtar MA, et al. Posterior uterine rupture causing fetal expulsion into the abdominal cavity: a rare case of neonatal survival. Case Rep Obstet Gynecol 2011;Article ID 426127:3.

[3] Landon MB, Hauth JC, Leveno KJ, et al. Maternal and perinatal outcomes associated with a trial of labor after prior cesarean delivery. $\mathrm{N}$ Engl J Med 2004;351(25):2581-9.

[4] Ofir K, Sheiner E, Levy A, et al. Uterine rupture: risk factors and pregnancy outcome. Am J Obstet Gynecol 2003;189(4):1042-6.

[5] Varras M, Christodoulos A. Posterior uterine wall rupture of an unscarred gravid uterus at 37 weeks of gestation: experience of a rare case with a review of the literature. Am J Case Rep 2010;11:20-3.

[6] Ronel D, Wiznitzer A, Sergienko R, et al. Trends, risk factors and pregnancy outcome in women with uterine rupture. Arch Gynecol Obstet 2012;285(2):317-21.

[7] Kadowa I. Ruptured uterus in rural Uganda: prevalence, predisposing factors and outcomes. Singapore Med J 2010;51(1):35-8.

[8] Majumdar S, Warren R, Ifaturoti O. Fetal survival following posterior uterine wall rupture during labour with intact previous caesarean section scar. Arch Gynecol Obstet 2007;276(5):537-40. 